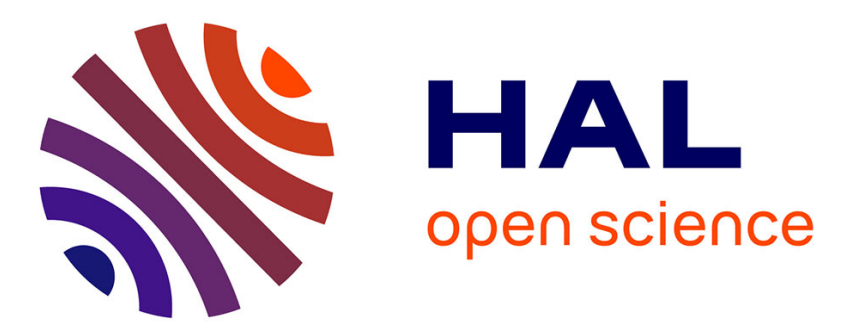

\title{
Orientations and seed type effect on Al2O3-YAG-ZrO2 eutectic microstructure solidified from the melt by the micro-pulling down technique
}

\author{
O. Benamara, K. Lebbou
}

\section{- To cite this version:}

O. Benamara, K. Lebbou. Orientations and seed type effect on Al2O3-YAG-ZrO2 eutectic microstructure solidified from the melt by the micro-pulling down technique. Journal of the European Ceramic Society, 2021, 41 (11), pp.5613-5623. 10.1016/j.jeurceramsoc.2021.04.047 . hal-03248508

\section{HAL Id: hal-03248508 \\ https://hal.science/hal-03248508}

Submitted on 8 Nov 2021

HAL is a multi-disciplinary open access archive for the deposit and dissemination of scientific research documents, whether they are published or not. The documents may come from teaching and research institutions in France or abroad, or from public or private research centers.
L'archive ouverte pluridisciplinaire HAL, est destinée au dépôt et à la diffusion de documents scientifiques de niveau recherche, publiés ou non, émanant des établissements d'enseignement et de recherche français ou étrangers, des laboratoires publics ou privés. 


\title{
Orientations and seed type effect on $\mathrm{Al}_{2} \mathrm{O}_{3}$-YAG- $\mathrm{ZrO}_{2}$ eutectic microstructure solidified from the melt by the micro-pulling down technique
}

\author{
O. Benamara, K. Lebbou \\ Institut Lumière Matière, UMR5306 Université Lyon1-CNRS, Université de Lyon, \\ 69622, Villeurbanne Cedex, France.
}

Corresponding author: kheirreddine.lebbou@univ-lyon1.fr

\begin{abstract}
$\mathrm{Al}_{2} \mathrm{O}_{3}-\mathrm{YAG}-\mathrm{ZrO}_{2}$ eutectic ceramic rods of $5 \mathrm{~mm}$ in diameter were grown by micro-pulling down technique. The seeding and the solidification rate affect microstructure, morphology, crystallography, and thermal stress of the solidified ceramics. The ternary eutectic grown through zirconia (111) seed had inhomogeneous and irregular cellular microstructures. At the stationary stable regime, the microstructure spacing $(\lambda)$ depends on the pulling rate $(v)$. Under solidification rate of $0.5 \mathrm{~mm} \cdot \mathrm{min}^{-1}$, the rods grown by using eutectic poly-crystal, (100), (111) YAG, and c(0001), A(1-210), M(10-10) sapphire seeds, the YAG and $\mathrm{ZrO}_{2}$ phases are oriented along the $\langle 100\rangle$ direction parallel to the growth direction. The zirconia (111) seeding $\mathrm{X}$-ray diagram eutectic presents additional peaks and the monoclinic $\mathrm{ZrO}_{2}$ phase appears at the solidification rate of $1 \mathrm{~mm}$.min-1. The rods grown through $\mathrm{ZrO}_{2}$ seeding are more stressed than those solidified by using eutectic, YAG and sapphire seeds, respectively.
\end{abstract}

Key words: Eutectic; Seed; Solidification, Microstructure; $\mu-P D$ 


\section{1- Introduction}

Unidirectional solidified eutectic oxides ceramics have a number of properties that make them of interest as potential engineering materials [1-3]. They can be considered as composite material elaborated from the melt with microstructures strongly affected by the solidification parameters [4]. An important advantage of unidirectional solidified eutectic for high temperature applications is that their microstructure is extremely stable, practically up to melting temperature [5,6]. This stability results from the facts that microstructures and morphologies were elaborated from the liquid state under thermodynamic equilibrium conditions [7]. If grain boundaries are present in the microstructure they are relatively, few in number and quite often parallel to the solidification direction [4]. Due to the physical and chemical limit of non-oxide materials at high temperature, eutectic ceramics with high melting point $\left(>1700^{\circ} \mathrm{C}\right)$, lower density $\left(4.5 \mathrm{~g} / \mathrm{cm}^{3}\right)$ and high thermal conductivity are an excellent alternative to these materials. In the recent years, important research have been conducted to improve the knowledge of the microstructure morphology aspect of the eutectic oxides solidified from the melt.

Among eutectic oxide ceramic, the $\mathrm{Al}_{2} \mathrm{O}_{3}-\mathrm{YAG}-\mathrm{ZrO}_{2}$ [8-12] ternary system is of great importance. Directional solidification of this system has been carried out previously and most of these studies have centered around Bridgman, Floating zone and micro-pulling down techniques $[13,14,15,16,17,18,19,20]$. The melting temperature is around $1750^{\circ} \mathrm{C}$, this system is stable and presents high-performance chemical and mechanical properties $[13,18]$. During the solidification from the eutectic point, growth of single-phase dendrites, colonies or cells are observed. Their presence are strongly connected to the solidification rate, axial thermal gradient along the growth direction and the chemical composition in $\mathrm{Al}_{2} \mathrm{O}_{3}-\mathrm{Y}_{2} \mathrm{O}_{3}-\mathrm{ZrO}_{2}$ equilibrium diagram.

In the case of $\mathrm{Al}_{2} \mathrm{O}_{3}-\mathrm{YAG}-\mathrm{ZrO}_{2}$ eutectic crystallisation, all phases are highly textured along preferred orientation. During eutectic solidification by using the micro-pulling down technique, when the growth rate became higher than $0.75 \mathrm{~mm} \cdot \mathrm{min}^{-1}$, the crystallographic orientations change completely $[19,20]$. Increasing the solidification rate results in a smaller grains size. The grains are chemically homogeneous and have either limited or no grain boundary segregation of impurities. In view of the advantage and the importance of this solidified system from the melt, the examination and the understanding of the growth parameters appears appropriate to control the performance and the application of this material. However, most of the previous research have been made to explore stability of the microstructure under different experimental processes. To our knowledge, there are not 
studies on the ternary eutectic microstructures and their stability as function of the seed type and its orientation. In this paper, the effect of the seed type on the microstructure formation in $\mathrm{Al}_{2} \mathrm{O}_{3}-\mathrm{YAG}-\mathrm{ZrO}_{2}$ eutectic solidified from the melt by using the micro pulling down technique was investigated.

\section{2- Experimental}

The samples were made from commercial high-purity (>99.99\%) $\mathrm{Al}_{2} \mathrm{O}_{3}, \mathrm{Y}_{2} \mathrm{O}_{3}$ and $\mathrm{ZrO}_{2}$ powders of nano-spherical shape. The powders were mixed in agate mortar at eutectic proportion according to the ternary eutectic composition $65 \mathrm{~mol} \% \mathrm{Al}_{2} \mathrm{O}_{3} \quad / 16 \mathrm{~mol} \% \mathrm{Y}_{2} \mathrm{O}_{3}$ $/ 19 \mathrm{~mol}_{2} \mathrm{ZrO}_{2}[21]$. The mixture was sintered at $1400^{\circ} \mathrm{C}$ for 10 hours in air.

Eutectic ceramics rods were solidified by the micro pulling down technique ( $\mu$-PD) and the experimental set-up was described in our previous works [19-20]. The growth process is carried out under flowing argon atmosphere. A CCD camera allows following in situ the growth process during all the experiments. Table 1 summarizes the different oriented sapphire, YAG and zirconia seeds used for the growth process. The rods are pulled under two pulling rates $\left(0.5\right.$ and $\left.1 \mathrm{~mm} \cdot \mathrm{min}^{-1}\right)$. The whole melt in the crucible is solidified, and the crucible is empty at the end of the solidification.

Table 1. Seeds used to initiate eutectic solidification

\begin{tabular}{|c|c|c|c|c|c|c|c|}
\hline Seed & $\begin{array}{c}\text { Standard } \\
\text { Eutectic }\end{array}$ & Sapphire & Sapphire & Sapphire & YAG & YAG & $\mathrm{ZrO}_{2}: \mathrm{Y}$ \\
\hline Orientation & Poly-crystal & $\mathrm{C}(0001)$ & $\mathrm{A}(1-210)$ & $\mathrm{M}(10-10)$ & $(100)$ & $(111)$ & $(111)$ \\
\hline
\end{tabular}

To study the homogeneity and the microstructures, samples are characterized along the rods. Longitudinally and transversally, cut pieces about 2 to $5 \mathrm{~mm}$ in length are embedded in organic resin and polished. The SEM observations of the rods are performed with a Phenom desktop Scanning Electron Microscope (SEM) at 5KV.

Room temperature X-ray diffraction characterization is used to define the purity and the crystallographic texture of the eutectic rods. The X-Rays diagrams are carried out using a Bruker D8 advanced diffractometer with $\mathrm{Cu}-\mathrm{K}_{\alpha 1}$ and $\mathrm{Cu}-\mathrm{K}_{\alpha 2} \mathrm{X}$-rays $(\lambda=0.15406$ and 0.15444 $\mathrm{nm})$. The diffraction diagram is scanned over a $2 \theta$ range from $15^{\circ}$ to $100^{\circ}$ in steps of $0.02^{\circ}$ with a counting time of $16 \mathrm{~s} / \mathrm{step}$ and continuous rotation $(120 \mathrm{rpm})$ for bulk measurement. The ${ }^{2} \mathrm{E} \rightarrow{ }^{4} \mathrm{~A}_{2}$ fluorescence lines of chromium $\left(\mathrm{Cr}^{3+}\right)$ ions as natural impurity in the $\mathrm{Al}_{2} \mathrm{O}_{3}$ host phase of the eutectic composite are used to evaluate the residual stresses in the solidified rods [22]. The displacements of the fluorescence lines of $\mathrm{Cr}^{3+}$ probe ions are measured at room temperature using a Horiba Jobin-Yvon micro-Raman spectrometer equipped with a CCD 
detector under confocal condition. A $473 \mathrm{~nm}$ laser wavelength is used as excitation source and focused on the surface of the sample through a 10X Olympus MIR plan objective with $0.25 \mathrm{NA}$ in order to cover a large sample area. For each measurement, the argon emission spectrum is recorded simultaneously for calibration and was used as external reference. For each sample, a 50 point of measurement are taken on different areas of the polished transversal section and small algorithm program was developed to calculate the position of R1, R2, argon peak and the errors measurement. Finally, all the measured spectra are fitted using a Gaussian profile in order to determine the exact peak positions of $\mathrm{Cr}^{3+}$ fluorescence lines.

\section{3- Results}

\subsection{Microstructure and morphology}

Fig. 1 shows the as solidified eutectic rods as a function of the seeds orientation. Controlled crystallization was obtained using pulling rates of 0.5 and $1 \mathrm{~mm} \cdot \mathrm{min}^{-1}$. The rods had a white color, macroscopic defects free (except with zirconia seeds), stable diameter $(\phi=5 \mathrm{~mm})$ and length around $100 \mathrm{~mm}$ depending on the starting charge in the crucible. Except solidification through eutectic seed, the growth behavior was quite difficult using YAG, zirconia and sapphire seeds. This was because of the crystallization interface, which spontaneously moves from the steady-state position, resulting in freezing of the rods at the crucible bottom, or disconnecting, especially when zirconia seeds are used. 


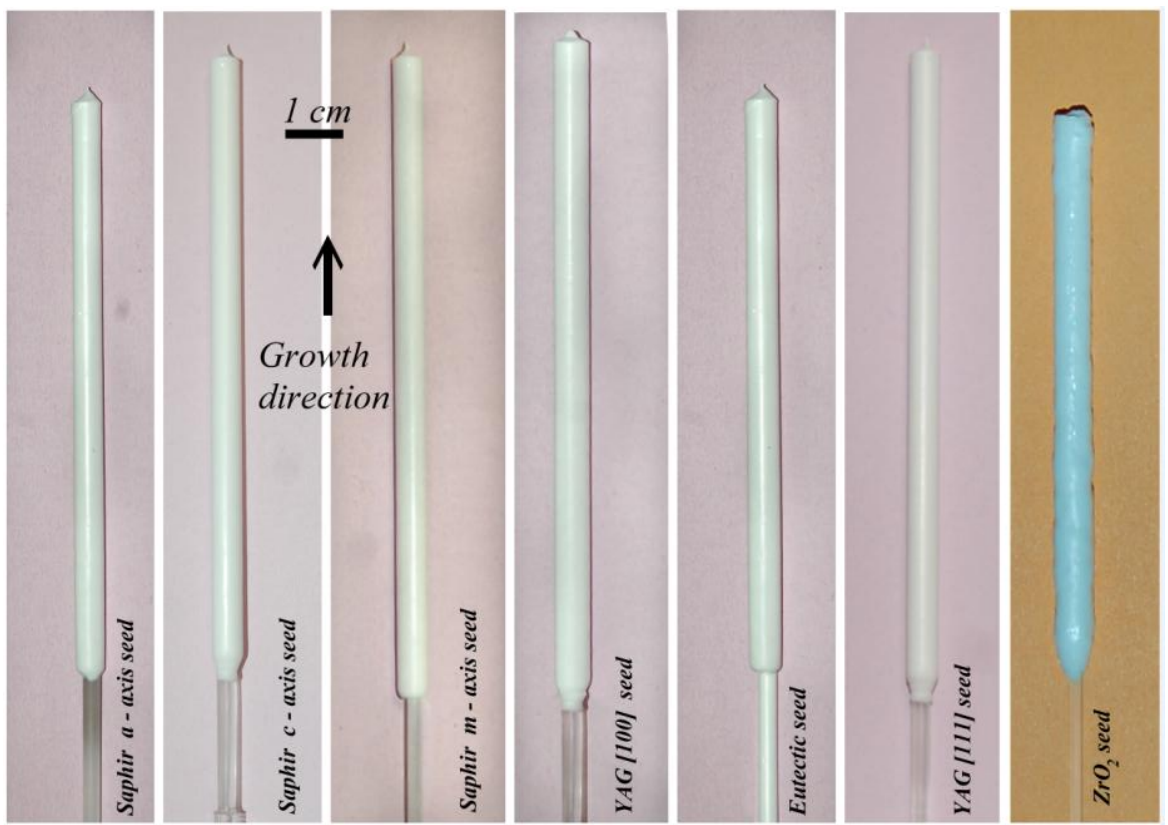

Figure 1. Eutectic rods as a function of the starting seed grown from the melt by the $\mu-P D$ technique $\left(\mathrm{v}=0.5 \mathrm{~mm} \cdot \mathrm{min}^{-1}\right)$.

The microstructural evolution can only be analyzed after interrupting the seeding solidification process. The detailed mechanisms by which the eutectic microstructures are found to be dependent on seeding is shown in figure 2. The microstructure and the morphology near the interface, the kinetics of solidification, the competition for the nucleation of phases and the nature of the successive phases formed are strongly affected by the seed type.

Whatever the initial seed, the system is initially filled with a binary system in the melt state with a composition $\mathrm{C}_{0}$, at a given temperature $\mathrm{T}$. Due to heat extraction from the seed, the average temperature of the system decreases and the solidification starts with a given undercooling. Three zones could be identified, the solid zone, mixture zone composed of liquid and solid phases and finally a fully liquid zone.

The crystallization of eutectic from the melt through seeding different than the eutectic seed causes a local change in the composition, which is due to the equilibrium condition between three phases $\left(\mathrm{Al}_{2} \mathrm{O}_{3}, \mathrm{YAG}, \mathrm{ZrO}_{2}\right)$. This difference between the phases distribution between 
the liquid and solid phases is connected to the solute redistribution or segregation, which has an important impact on the final microstructure as well as on the phase's volume fraction.

For this ternary eutectic system, the microstructure can be Chinese script, geometrical pattern, regular or irregular growth as a function of the growth parameters and the entropy of fusion (Table 2) of the three solid phases growing together [23]. On one hand, in the $\mathrm{Al}_{2} \mathrm{O}_{3}-\mathrm{YAG}$ $\mathrm{ZrO}_{2}$ ternary system, the entropies of fusion of YAG and $\mathrm{Al}_{2} \mathrm{O}_{3}$ are much higher than $2 \mathrm{R}$ $\left(\mathrm{R}=8.3144 \mathrm{~J} \mathrm{~mol}^{-1} \mathrm{~K}^{-1}\right.$ ), so they present strongly faceted growth. On the other hand, the $\mathrm{ZrO}_{2}$ entropy of fusion is close to $2 \mathrm{R}$, so the growth is slightly faceted and form rods or lamellae morphology.

Table 2. Melting entropies of $\mathrm{YAG}, \mathrm{Al}_{2} \mathrm{O}_{3}$ and $\mathrm{ZrO}_{2}$ oxides.

\begin{tabular}{|l|c|c|c|}
\cline { 2 - 4 } \multicolumn{1}{c|}{} & $\mathrm{YAG}\left(\mathrm{Y}_{3} \mathrm{Al}_{5} \mathrm{O}_{12}\right)$ & $\mathrm{Al}_{2} \mathrm{O}_{3}$ & $\mathrm{ZrO}_{2}$ \\
\hline $\mathrm{S}_{\text {melting }}\left(\mathrm{J} \mathrm{K}^{-1} \mathrm{Mol}^{-1)}\right.$ & 122 & 48 & 30 \\
\hline
\end{tabular}

An interesting observation to point out when considering all connection steps in figure $\mathbf{2}$ is a systematic correlation between zirconia distribution and seeding. At the beginning of the growth, the average concentration of zirconia is higher when connection is realized through sapphire seed and the solidification process is very close to $\left(\mathrm{Al}_{2} \mathrm{O}_{3}-\mathrm{ZrO}_{2}\right)$ binary system [24]. As observed in Figure 2, the size of $\mathrm{ZrO}_{2}$ phase in $\mathrm{Al}_{2} \mathrm{O}_{3}$ matrix is larger than that corresponding size in the standard $\mathrm{Al}_{2} \mathrm{O}_{3}-\mathrm{YAG}-\mathrm{ZrO}_{2}$ ternary eutectic [19]. There is a delay of YAG precipitation appearing after $30 \mu \mathrm{m}$ of growth for sapphire a-axis seed and around 50 $\mu \mathrm{m}$ for $\mathrm{c}$ and $\mathrm{m}$-axis, respectively. The most part of YAG accumulated in the interface starts to reach saturation, the solidification front is destabilized and a strong projection of YAG into the melt is accompanied by random YAG phase precipitation. The coarseness of the YAG into the melt is due to its entropy of fusion higher than $\mathrm{Al}_{2} \mathrm{O}_{3}$ and $\mathrm{ZrO}_{2}$ phases. It is clearly seen that the variation of the zirconia size is narrower when $\mathrm{c}$ and $\mathrm{m}$-axis sapphire seeds are used. After few time, nucleation and growth of the eutectic microstructure start. This could be explained by the important thermal gradient after the connection by sapphire seed. Another hand, in addition, using eutectic and YAG seeds, the priming of the solidification process is controlled through $\mathrm{Al}_{2} \mathrm{O}_{3}$-YAG binary system [25]. The microstructure is mainly composed of YAG lamella, sapphire and few $\mathrm{ZrO}_{2}$ particles imbedded on YAG interface. The same scale is used for all seed connection. 

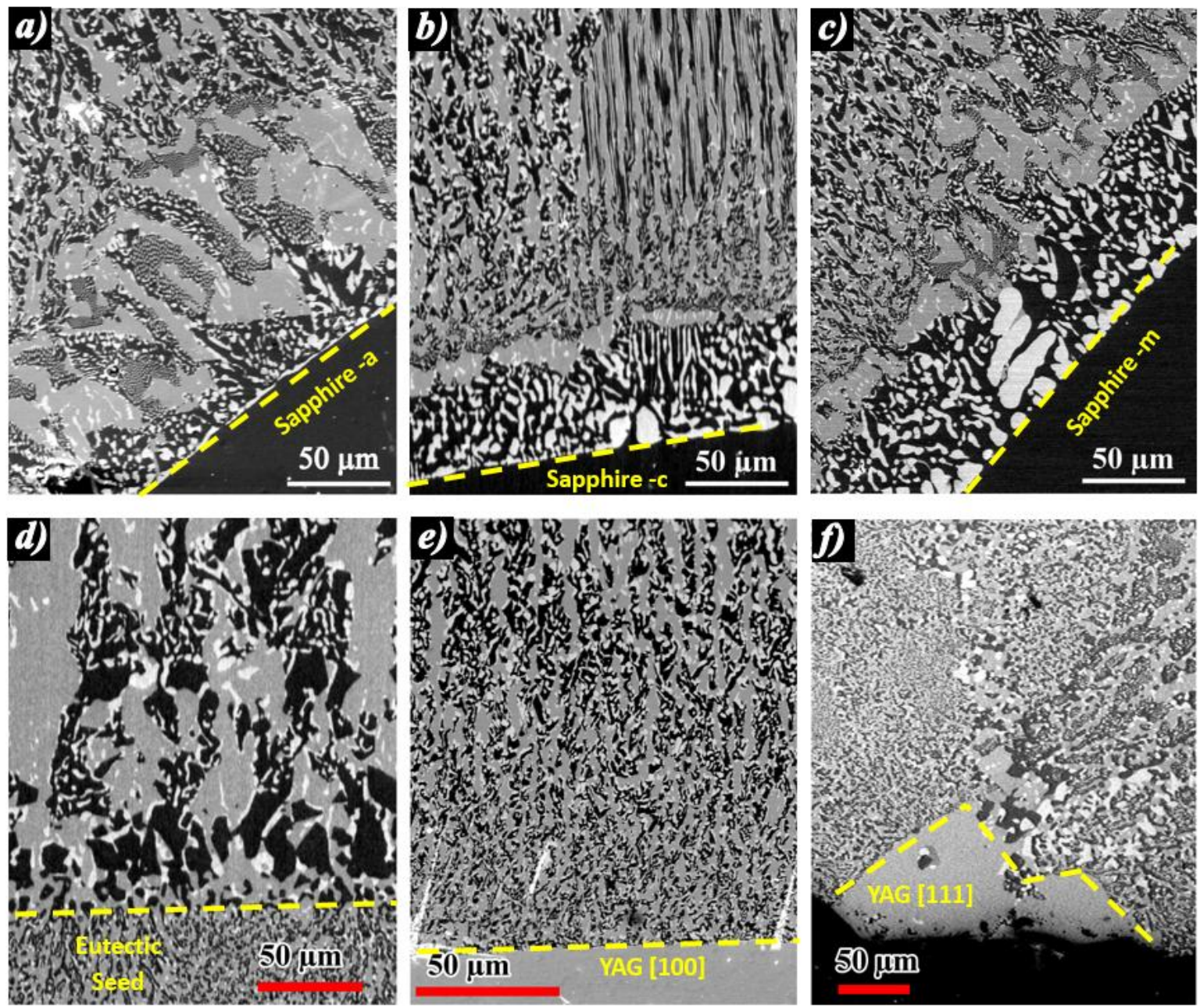

Figure 2. Impact of seeding and the first step of the growth as a function of the seed orientations: (a) M(10-10) sapphire, (b) c(0001) sapphire, (c) M(10-10) sapphire, (d) Eutectic ; (e) YAG [100], (f)YAG [111]. The black color corresponds to $\mathrm{Al}_{2} \mathrm{O}_{3}$ phase, the gray is YAG and the white correspond to $\mathrm{Y}-\mathrm{ZrO}_{2}$ phase.

The evolution of each grain can be individually followed during the solidification process. As a function of seeds, experimental observation tend to show how the different phases interact in the melting zone near the crystallization interface. Figure 3 shows the film, where some grains can be seen in the molten zone as well as their movements before and after incorporation in the rod. In the case of eutectic seeding, the liquid is homogeneous in the front of crystallization interface and we have not seen any particles movement in the melting zone. The crystallization front is plane from the beginning $(\mathbf{t}=\mathbf{4}$ '15"), the stationary stable growth regime is reached after few minutes (6'08') of pulling (Fig 3c) and the growth doesn't introduce any undercooling or meniscus length increasing (Fig.3d). The situation is completely different when sapphire, YAG and $\mathrm{ZrO}_{2}$ seeds are used. In Fig.3e corresponding 
to sapphire M(10-10) seeding, after 4:40 minutes of growth (Fig.3f) two elongated grains (white color) are observed near the center of the crystallization interface as well as their movement and interaction before incorporation in the $\operatorname{rod}(\mathbf{t}=\mathbf{6 : 5 5 m}, \mathbf{F i g . 3 g})$. It should be noted that we have observed irregular grain coalescence until complete penetration in the eutectic rod. The liquid is a bit electrically conductive [26], electrostatic effects are likely to play a role in the stabilization of the grains position close to the interface. The overall force acting on the grain is apparently large enough to prevent the grains from flowing upward. After 8' 41' (Fig 3i), the coalesced grain was completely incorporated in the rod and stable growth with slightly convex interface is observed. Whatever sapphire seed orientation, the SEM images (Fig 2) showed zirconia particles are the most dominated phase at the beginning of the growth. Fig $\mathbf{3}(\mathbf{j} \rightarrow \mathbf{m})$ shows direct observation of the grains propagation and the phase's nucleation through YAG seeding. The main drawback is the difficulty to measure the thermal history of an individual grain during its apparition, coalescence and penetration in the rod. After connection (Fig.3j) and 4:31m later (Fig.3k), few grains appear in the melting zone and

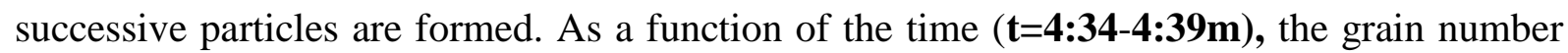
increases and the average size varied from few $\mu \mathrm{m}$ to hundred $\mu \mathrm{m}$ (Fig 3i, 9m). The progression and the shape of the visible grains in the melting zone are found closely correlated to the pulling rate, also explaining the geometry of the crystallization front. As the entropy of fusion of YAG is the higher one, the observed grown grains (Fig.3m) in the melting zone are expected to be YAG in good argument with SEM image of YAG seeding (Fig.2). In addition, the coalescence along the solidification axis are expected to the formation of YAG lamella as it is observed at the crystallization interface. The examination of this region of the samples revealed directional but poorly oriented microstructures. Extensive nucleation of new grains occurred near the solidification front, but these grains were only approximately oriented. At least more than $100 \mu \mathrm{m}$ of solidification is required before the better-oriented grains began to predominate, but soon after, the grain orientation became random and eutectic microstructure appears. The thermal gradient at the interface is high and the crystallization interface is convex. However, the thermal gradient decrease as the amount of the solidification increases. The decreasing of the interface thermal gradient resulted from the increasingly effective thermal insulation presented by the solidified eutectic along the growth direction. After few minutes of solidification, the interface crystallization becomes flat and stationary stable growth is observed.

By using $\mathrm{ZrO}_{2}$ seed (Fig. 3n), a lot of tentative of seeding has been done to prime the solidification process. It was quite difficult to obtain melting zone and mix $\mathrm{ZrO}_{2}$ seed with 
eutectic melt because of the $\mathrm{Zr}^{4+}$ charge higher than $\mathrm{Al}^{3+}$ and $\mathrm{Y}^{3+}$. Until proven otherwise, may be liquid immiscibility control the beginning of the solidification. In Fig 3o, after the first period of connection ( $\mathrm{t}=\mathbf{1 1} \mathbf{s})$, spherical particles remained stable very close or contacting the solid-liquid interface. However, in a second step, after 23s (Fig.3p) the particles in the center of the image start to oscillate in the molten zone until fragmentation in two particles followed by penetration in the rod. The color contrast of the liquid changes and new particle appears at the center of the interface. After 7min53s (Fig.3q), a small particle connected to the interface appears. The change from small particle to lamella ( $\mathrm{t}=9 \mathrm{~min} 23 \mathrm{~s})$ is shown primarily by the diffusion requirements in growth (Fig .3r). Few second later (10min01s), a cooperative growth phenomena is observed and two lamellas grow with a common interface (Fig.3s). The cooperative growth of the two lamellas with a common interface can be shown to be faster process than either phase individually. After 12min: 23s, the growth indicates instability of the edge of the lamella (Fig. 3t). Therefore, only one of the lamella of the unstable edge will grow and again become unstable until complete fragmentation after 12min36s (Fig.3u). The quantity of the crystallized lamellas near the solidification front increase with time (Fig 3v, 3w). After growth and cooling down, it was possible to find back those particles at the beginning of the grown rod. The phase's precipitates are mainly $\mathrm{ZrO}_{2}: \mathrm{Y}$ and sapphire Lamella's.

It is important to note that we use iridium crucible, so we have note reaction of the melt with crucible. Chemical reactions of oxide $\left(\mathrm{Al}_{2} \mathrm{O}_{3}, \mathrm{Y}_{2} \mathrm{O}_{3}, \mathrm{ZrO}_{2}\right)$ in the growth chamber, in order to produce $\mathrm{CO}$ gas, are not possible in our case where no graphite parts are used in the chamber. The incorporation of the grains in solidifying rod as a function of seeding is a very important phenomenon, which we followed during the solidification process. Most likely various mechanism play a role in this phenomenon like instability of the liquid as a function of seeding, local thermal or chemical effects, capillarity, viscous drag, thermal conductivity of the particles, or chemical segregation. In comparison to the others seeds (Eutectic, Sapphire, YAG), the $\mathrm{ZrO}_{2}$ seeding has a memory effect on the stability of the microstructure and the morphology. 

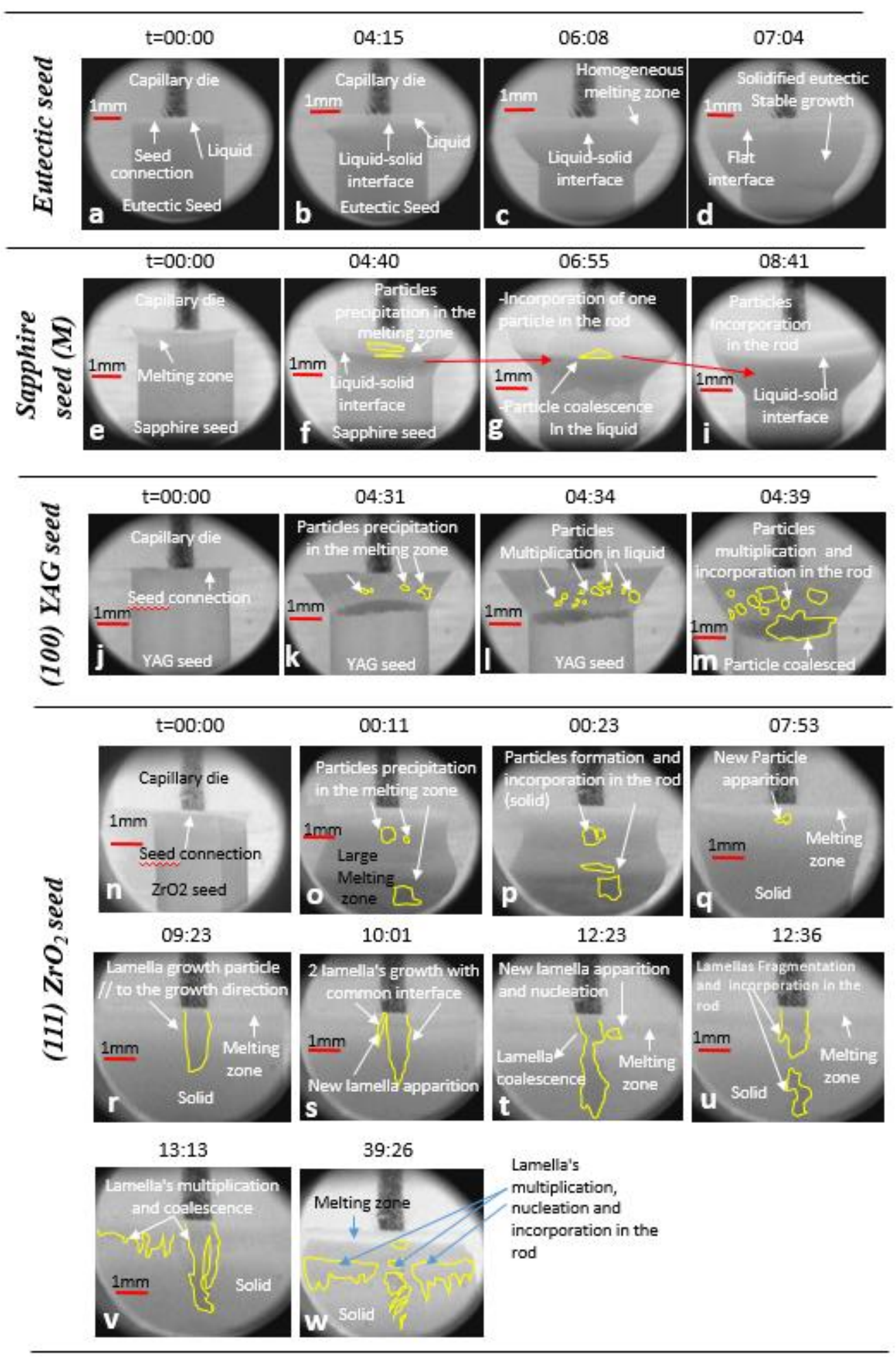

Figure 3. Video sequence of the melt behavior, particles precipitation and the different steps before their incorporation in the rods as a function of the seeds. Diameter of the capillary die at the bottom of the crucible is $5 \mathrm{~mm}$.

Figure 4 and Figure 5 show the transversal and longitudinal SEM images of the eutectic microstructures $4 \mathrm{~cm}$ from the seed connection. The eutectic microstructure is composed of three phases distinguished by their different geometries and colors. The black matrix 
corresponds to $\mathrm{Al}_{2} \mathrm{O}_{3}$ phase, and the gray phase is $\mathrm{YAG}\left(\mathrm{Y}_{3} \mathrm{Al}_{5} \mathrm{O}_{12}\right)$. The zirconia phase appears as a fine homogeneous dispersion of precipitates at the YAG interfaces. Part of the zirconia is distributed over the alumina matrix. As a function of the seeds and the pulling rates, although many solidification experiments are carried out, Chinese script eutectic microstructures are observed in all cases. Transverse view of the eutectic microstructures shows that the microstructures crystallized at pulling rate of $1 \mathrm{~mm} \cdot \mathrm{min}^{-1}{ }^{1}$ are smaller than those pulled at slower solidification rate $\left(0.5 \mathrm{~mm} \cdot \mathrm{min}^{-1}\right)$, which is the expected behavior.

At solidification rate $0.5 \mathrm{~mm} \cdot \mathrm{min}^{-1}$, whatever the seed types and their orientation, homogeneous Chinese script microstructure and coupled eutectic growth are observed. Some instability involving the formation of colonies are observed in all the samples. This instability problem has been observed by many researcher [27, 28, 29,30]. It is based on the competitive growth kinetic in which leading phase is the one that is growing at higher interface temperature. The formation of colonies has been shown to occur due to the presence of nonplanar eutectic growth interface [31, 32,33]. As shown in figure 4, the solidified eutectic using eutectic seed under the same conditions presents a slight magnification of the phases.

The zirconia phase appears as a fine homogeneous dispersion of precipitates at the YAG interfaces. Part of the zirconia is distributed over the alumina matrix. Under solidification rate of $1 \mathrm{~mm} \cdot \mathrm{min}^{-1}$, a change in morphology at the center of the colonies in the samples solidified through YAG (100) and sapphire (0001) seeds. Fig. 4h, 4k $5 \mathbf{h}$ and 5k show the Geometrical Pattern microstructure formed at the center of the colonies. Then approaching the edge of the colonies, the Chinese Script microstructure is formed. The phases have a very angular appearance. The zirconia is in the form of a fiber inside the $\mathrm{Al}_{2} \mathrm{O}_{3}$ phase close to the $\mathrm{Al}_{2} \mathrm{O}_{3}-\mathrm{ZrO}_{2} \mathrm{Y}$ binary system $[15,18,34]$. At pulling rate of $1 \mathrm{~mm} \cdot \mathrm{min}^{-1}$, the colony microstructure merged into nearly homogeneous cell structure with lamellae. Except the rods pulled by the eutectic seed (Fig5a,5g) a strong elongation of the microstructure is observed along the direction of solidification as shown by the observation in longitudinal section presented in figure 5. No striation defect, which would divide the connection of the rods along the growth direction were observed in any sample. 

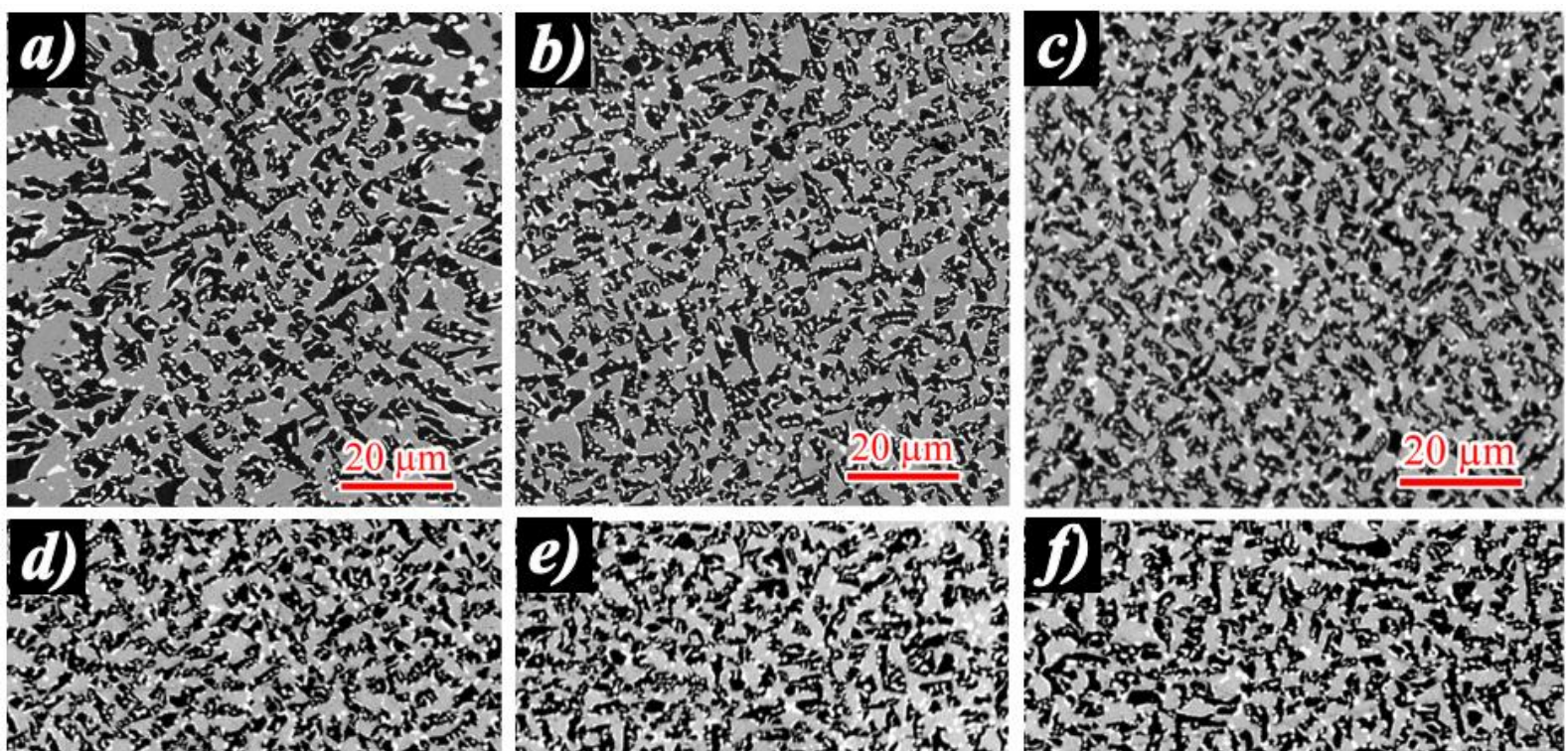

S.
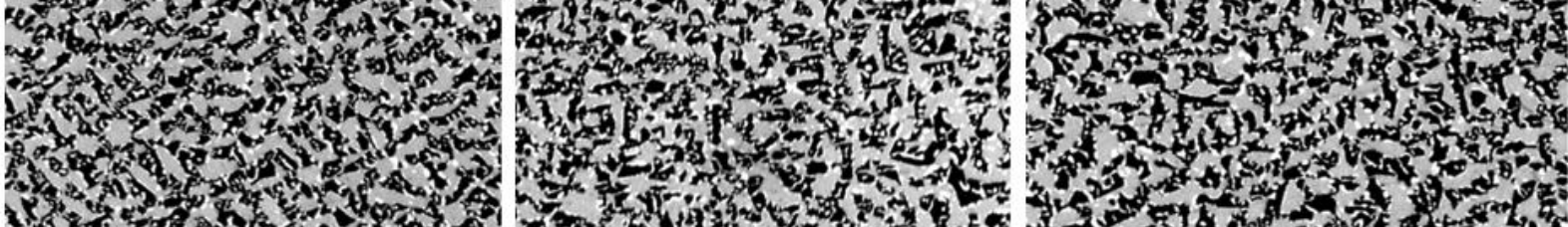

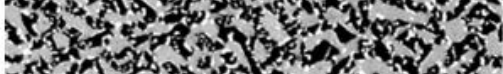
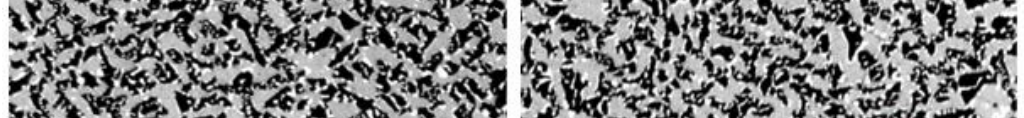

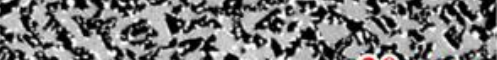
2.
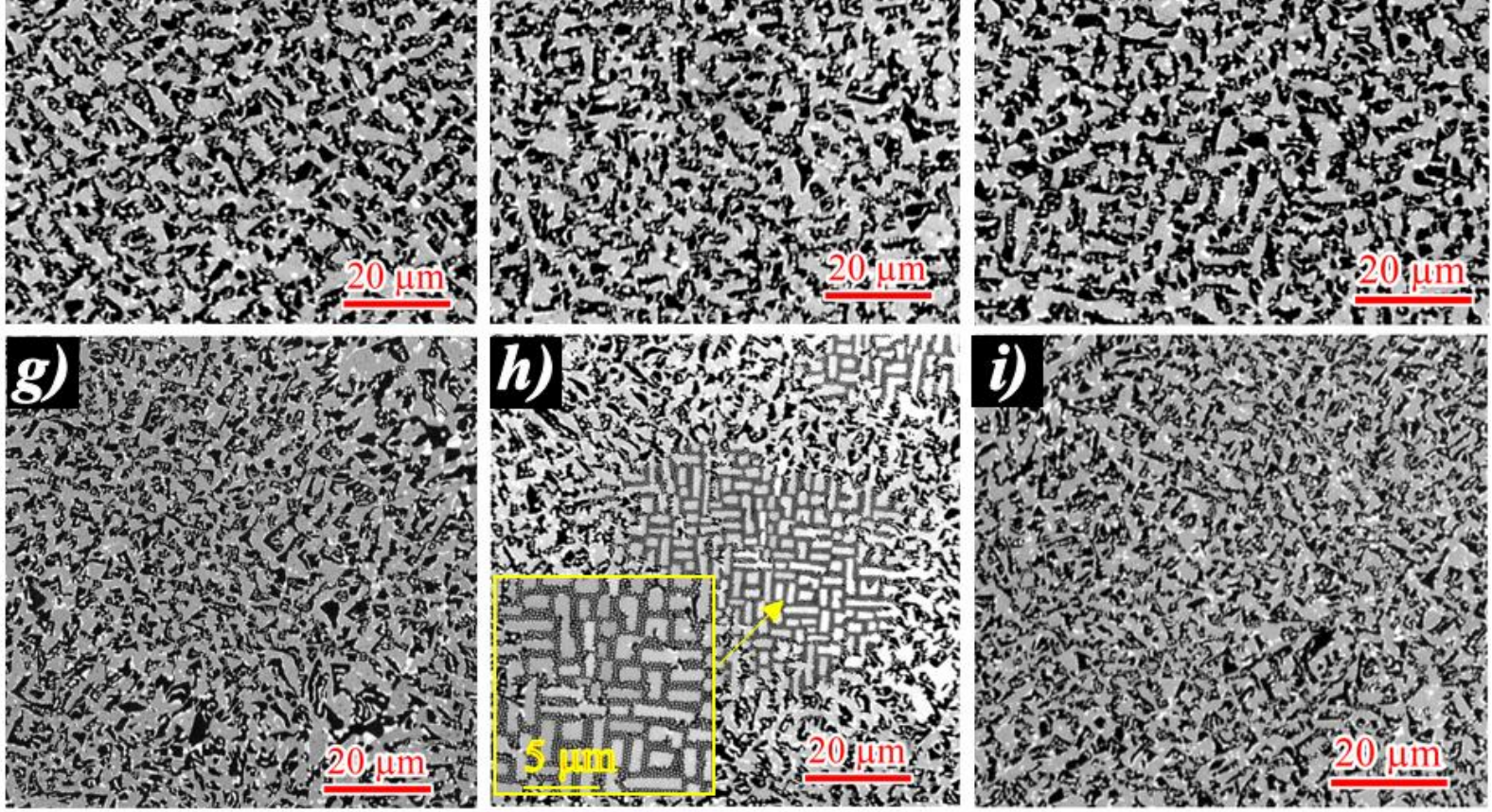

50 s.

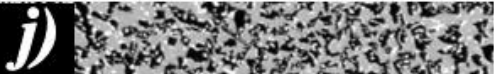

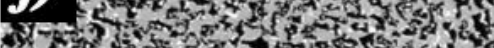

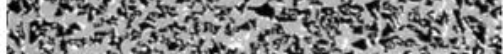
Y.F,

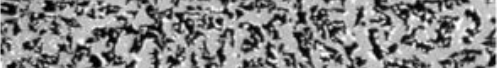
H. H. 2.

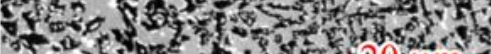

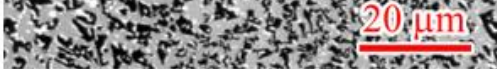

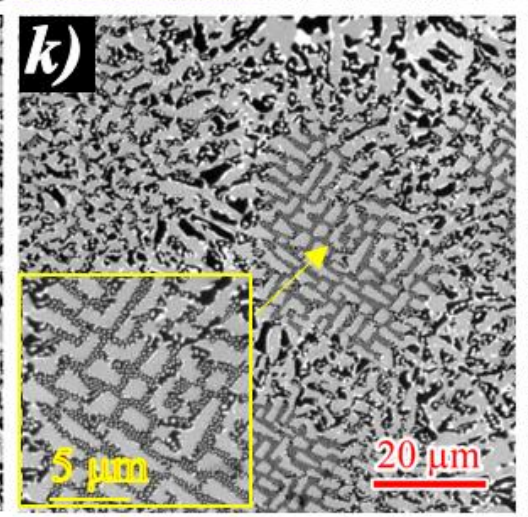

i) 5 at 4 is

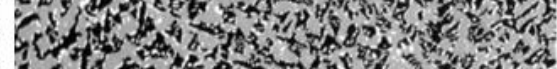

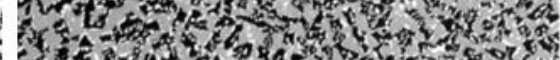

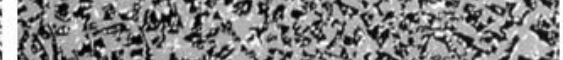

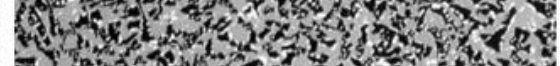
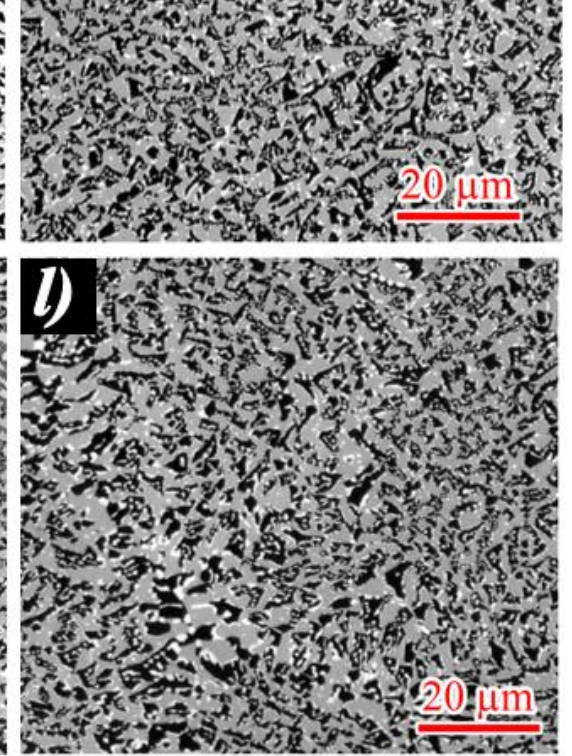

Figure 4. Transversal microstructure evolution as a function of the seeds types and pulling rates.

(a,b,c,d, e,f) correspond to $\mathrm{v}=0.5 \mathrm{~mm} / \mathrm{min},(\mathrm{g}, \mathrm{h}, \mathrm{i}, \mathrm{j}, \mathrm{k}, \mathrm{l})$ correspond to $\mathrm{v}=1 \mathrm{~mm} \cdot \mathrm{min}^{-1}$

$(\mathrm{a}, \mathrm{g})$ : eutectic seed, (b,h): (100) YAG seed, (c,i): (111) YAG seed, (d,j): A(1-210) sapphire seed, (e,k): c(0001) sapphire seed, (f,l): ), M(10-10) sapphire seed. 

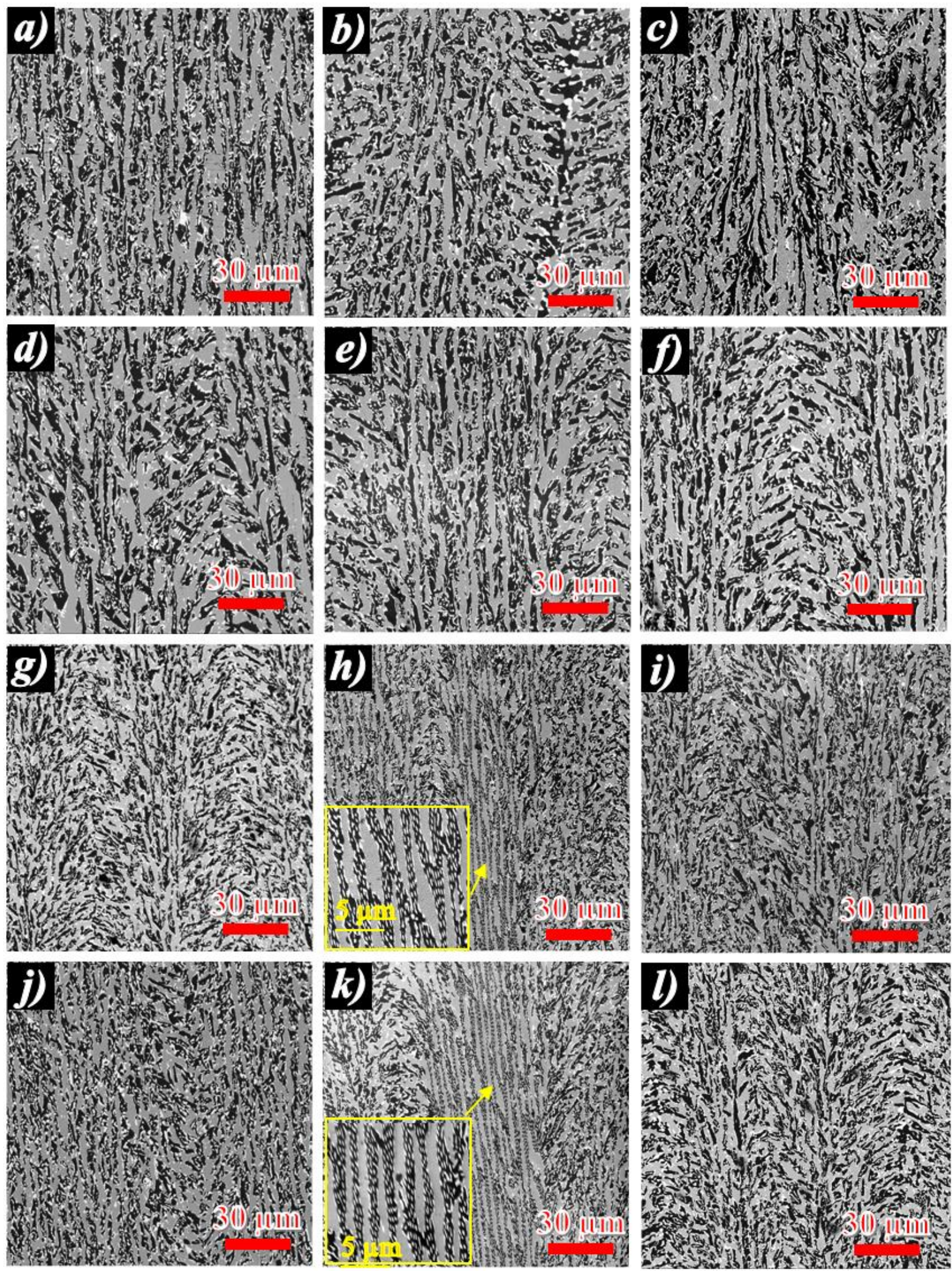

Figure 5. Longitudinal microstructure evolution as a function of the seed types and pulling rates.

(a,b,c,d, e,f) correspond to $\mathrm{v}=0.5 \mathrm{~mm} \cdot \mathrm{min}^{-}{ }^{1},(\mathrm{~g}, \mathrm{~h}, \mathrm{i}, \mathrm{j}, \mathrm{k}, \mathrm{l})$ correspond to $\mathrm{v}=1 \mathrm{~mm} \cdot \mathrm{min}^{-1}$

$(\mathrm{a}, \mathrm{g})$ : eutectic seed, (b,h): (100) YAG seed, (c,i): (111) YAG seed, (d,j): A(1-210) sapphire seed, (e,k): c(0001) sapphire seed, (f,l): ), M(10-10) sapphire seed. 
Figure 6 shows the transversal and longitudinal SEM images of the eutectic microstructures solidified through (111) $\mathrm{ZrO}_{2}$ seed after pulling $40 \mathrm{~mm}$ of the rod. It is difficult to control the microstructure and the morphology of the growth seeded through zirconia seed. Eutectic solidified using zirconia seed show instabilities of the microstructures. The oscillating structures are predicted at off-eutectic composition. A large irregular cellular microstructure limited by $\mathrm{ZrO}_{2}$ border are observed. The cell walls are relatively weak and contain higher concentration of $\mathrm{ZrO}_{2}$. The cells solidified at pulling rate of $0.5 \mathrm{~mm} \cdot \mathrm{min}^{-1}$ are larger than those grown at $1 \mathrm{~mm} \cdot \mathrm{min}^{-1}$.

The microstructure crystallized at pulling rate of $1 \mathrm{~mm} \cdot \mathrm{min}^{-}{ }^{1}$ is smaller than that solidified at slower solidification rate $\left(0.5 \mathrm{~mm} \cdot \mathrm{min}^{-1}\right)$. In comparison with the typical eutectic microstructure and the samples grown by using eutectic, sapphire and YAG seeds, for both pulling rate poor microstructures are obtained and $\mathrm{ZrO}_{2}$ particles are randomly dispersed in $\mathrm{Al}_{2} \mathrm{O}_{3}$ matrix. Few amount of $\mathrm{ZrO}_{2}$ particles are imbedded on YAG interface different that seeding sapphire, YAG and eutectic seeds. Whatever the pulling rates, some $\mathrm{ZrO}_{2}$ particles are crystalized in lamella shape of length up to $50 \mu \mathrm{m}$. At pulling rate $0.5 \mathrm{~mm} \cdot \mathrm{min}^{-1}$ some zirconia particles have a fibrous structure. The sapphire grows in a lamellar manner and $\mathrm{ZrO}_{2}$ prefers to grow in the $\mathrm{Al}_{2} \mathrm{O}_{3}$ phase. This is connected to the melt excess of $\mathrm{ZrO}_{2}$ phase coming from the melted part of $\mathrm{ZrO}_{2}$ seed at the beginning of connection.

EDX measurements of the aluminum, yttrium and zirconium are performed on different regions of the samples solidified through eutectic polycrystalline seed and YAG, Sapphire and $\mathrm{ZrO}_{2}$ single crystals seeds. Except $\mathrm{ZrO}_{2}$ grains which exhibit an important concentration of yttrium atoms due to the substitution of $\mathrm{Zr}$ by $\mathrm{Y}$ in $\mathrm{ZrO}_{2}$ phase, all the composition analysis of YAG $\left(\mathrm{Y}_{3} \mathrm{Al}_{5} \mathrm{O}_{12}\right)$ and $\mathrm{Al}_{2} \mathrm{O}_{3}$ phases are very close to the theoretical stoichiometric composition. The presence of $\mathrm{Zr}$ in $\mathrm{YAG}$ and sapphire phases corresponds to the accuracy measurement $(<1 \%)$. The average of yttrium oxide $\left(\mathrm{Y}_{2} \mathrm{O}_{3}\right)$ composition in YZT phase measured by EDX is about $19 \mathrm{~mol} \% \pm 3 \%$. It is the necessary concentration to stabilize cubic zirconia $\left(\mathrm{ZrO}_{2}\right)$ phase. In the samples solidified using zirconia seed and pulling rate $1 \mathrm{~mm} . \mathrm{min}^{-}$ ${ }^{1}$ we registered some $\mathrm{Y}$-doped $\mathrm{ZrO}_{2}$ traces of low $\mathrm{Y}_{2} \mathrm{O}_{3}$ concentration $(<1.5 \mathrm{~mol} \%)$ susceptible to correspond to monoclinic phase in good agreement with Ref [35]. These traces of monoclinic $\mathrm{Y}-\mathrm{ZrO}$ particles are observed at the colonies periphery.

Eutectic spacing's $(\lambda)$ are measured as a function of the seed type, orientation and pulling rate (Figure 7). The variation with growth rate is found to show more significant deviation than the seed type and orientation. The eutectic spacing is found to decrease with increasing pulling rate in good agreement with references $[19,20]$. The lamellar eutectic growth revealed 
that the spacing eutectic is not very sharp and a band of stable interlamellar spacing is distributed under pulling rates 0.5 and $1 \mathrm{~mm} \cdot \mathrm{min}^{-1}$.
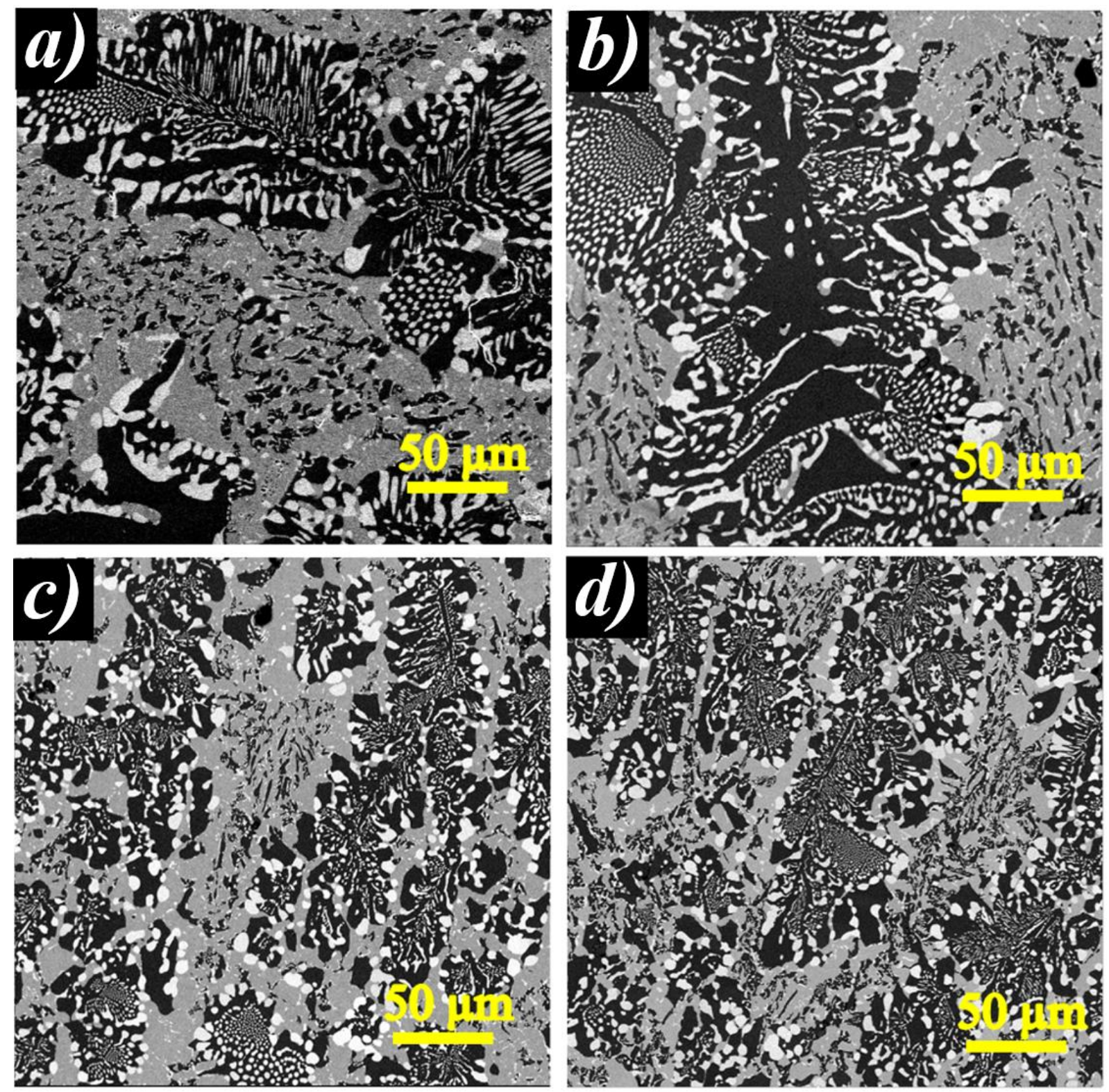

Figure 6. Microstructure evolution of eutectic solidified through (111)zircnia seeding.

-Transversal section: ((a) $\mathrm{v}=0.5 \mathrm{~mm} \cdot \mathrm{min}^{-1}$,(b) $\left.\mathrm{v}=1 \mathrm{~mm} \cdot \mathrm{min}^{-1}\right)$ )

-Longitudinal section: ((c) v=0.5 mm. $\mathrm{min}^{-1}$,(d) $\left.\mathrm{v}=1 \mathrm{~mm} \cdot \mathrm{min}^{-1}\right)$ ) 


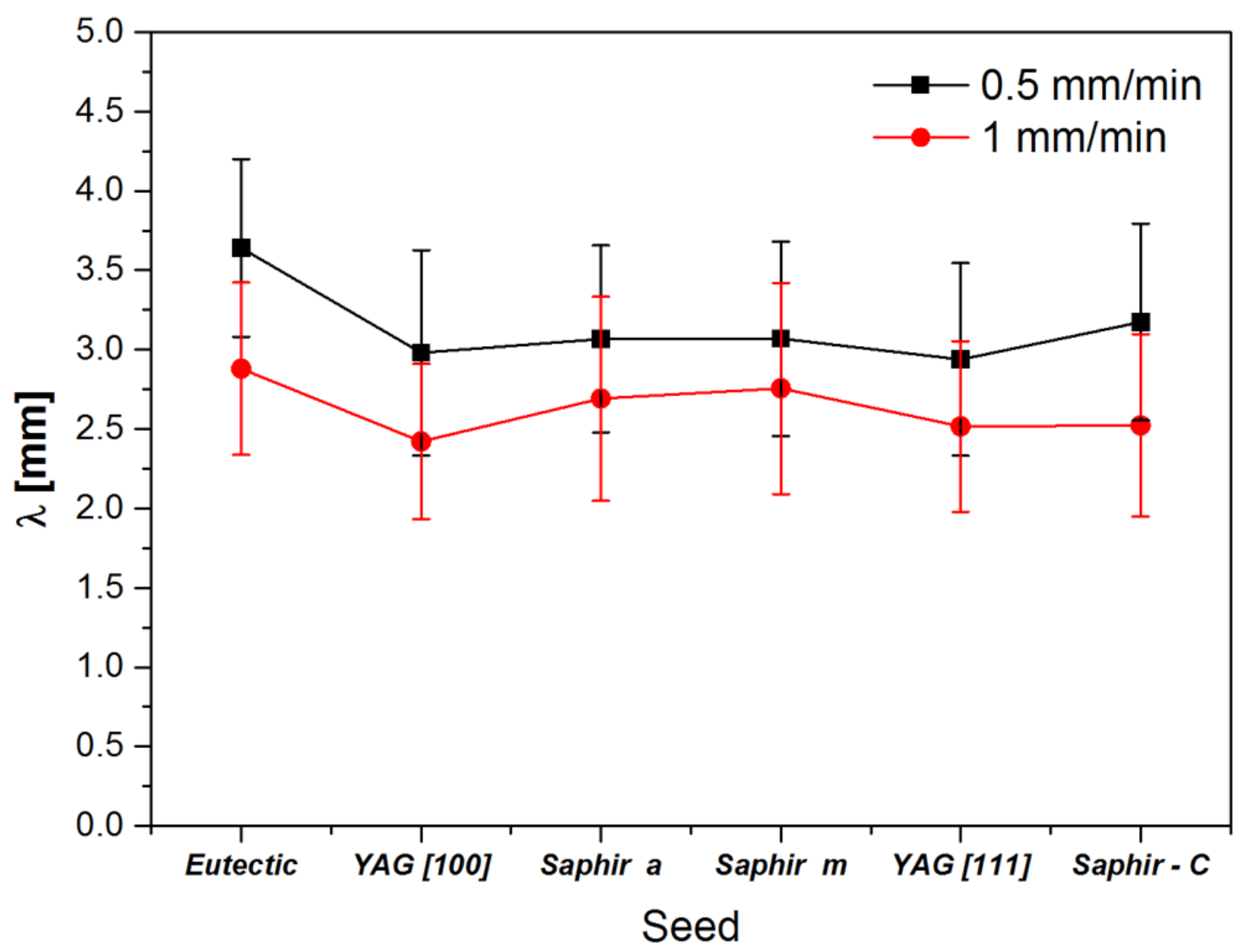

Figure 7. Eutectic spacing variation as a function of seeds and pulling rates

\section{3-2 Crystallography}

Fig. 8 shows room temperature X-ray diffraction patterns of the eutectic transversal section rods as a function of the seeds and the pulling rate. They often grow preferentially along welldefined crystallographic orientations. Except zirconia seeding, for pulling rate of $0.5 \mathrm{~mm} . \mathrm{min}^{-}$ ${ }^{1}$ the preferred growth orientation of $\mathrm{Al}_{2} \mathrm{O}_{3}$ is (01-10), that of YAG is (100) and that of $\mathrm{ZrO}_{2}$ is $(100)$ which are in good agreement with that reported in references $[\mathbf{1 4 , 3 6}]$. For the pulling rate of $1 \mathrm{~mm} \cdot \mathrm{min}^{-1}$, as a function of the seeds (except with zirconia seeds), the crystallographic planes became (01-12) for $\mathrm{Al}_{2} \mathrm{O}_{3},(100)$ and additional YAG garnet peaks for YAG phase, and finally (110) (420) for zirconia phase. For both pulling rates, in case of zirconia seed, the Xray diagrams are different than others seeds orientations. The samples present additional YAG, $\mathrm{Al}_{2} \mathrm{O}_{3}$ and $\mathrm{ZrO}_{2}$ peaks showing others crystallographic orientations. There is a distinct difference between the zirconia seeds X-ray diagram and the others seeds concerning the presence of peak of $\mathrm{ZrO}_{2}$ (311). No apparent peak of $\mathrm{ZrO}_{2}$ (311) have been seen in the rods solidified through eutectic, sapphire and YAG seeds. The $\mathrm{Al}_{2} \mathrm{O}_{3}(01-12)$ and (02-24) peaks observed in rods solidified at $1 \mathrm{~mm} \cdot \mathrm{min}^{-1}$ through eutectic, sapphire and YAG seeds are not observed in the rods grown at $0.5 \mathrm{~mm} \cdot \mathrm{min}^{-1}$ and zirconia seeding for both pulling rates. 
The rod grown at pulling rate of $1 \mathrm{~mm} \cdot \mathrm{min}^{-1}$ by zirconia seed contains two additional peaks (011) and (-102) belonging to the zirconia monoclinic phase. According to the $\mathrm{ZrO}_{2}-\mathrm{Y}_{2} \mathrm{O}_{3}$ binary phase diagram [37], only cubic $\mathrm{ZrO}_{2}$ is stable for $\mathrm{Y}_{2} \mathrm{O}_{3}$ greater than $8 \mathrm{~mol} \%$. For lower compositions tetragonal or monoclinic $\mathrm{ZrO}_{2}$ are formed. In $\mathrm{ZrO}_{2}$ compound, the formation of the monoclinic structure is athermal, diffusionless and shear displacive. This transformation can be stress induced because of the strong thermal gradient regarding the high pulling rate (1 $\mathrm{mm} \cdot \mathrm{min}^{-1}$ ). The presence of the monoclinic $\mathrm{ZrO}_{2}$ phase can be explained by two hypothesis: 1-The melting temperature of zirconia $\left(2600^{\circ} \mathrm{C}\right)$ is higher than melting temperature of sapphire $\left(2050^{\circ} \mathrm{C}\right)$ and $\mathrm{YAG}\left(1980^{\circ} \mathrm{C}\right)$. Approaching zirconia seed to melting zone will extract the heat (melt temperature decreases) causing larger thermal gradient and consequently faster growth rate can be attained in the melting zone. The liquid on the surface is sufficiently undercooled to destabilize the cubic zirconia and precipitate the monoclinic phase.

2- Precipitation of the monoclinic phase is a function of particles size and shape, thermal properties of the particles and its surrounding matrix. The monoclinic phase formation will occur if the surface energy and yttrium concentration favor its precipitations. In Figure 6a, the small $\mathrm{ZrO}_{2}$ particles emerged in alumina matrix at the border of the cells could be the driving force for the monoclinic phase formation. The utilization of $\mathrm{ZrO}_{2}$ seed to initiate the solidification from the melt at pulling rate $1 \mathrm{~mm} \cdot \mathrm{min}^{-1}$ causes an off eutectic composition (zirconia enrichment) at the connection zone near the crystallization interface. This behavior affect the shape of the crystallization front and the composition of the melting zone favoring the destabilization of cubic zirconia and the precipitation of the monoclinic phase.

It should be noted that the monoclinic $\mathrm{ZrO}_{2}$ in the $\mathrm{Al}_{2} \mathrm{O}_{3}-\mathrm{Y}_{2} \mathrm{O}_{3}-\mathrm{ZrO}_{2}$ ternary eutectic composition was never reported before and its origin is not fully understood. Further experimental work is required to look if the zirconia destabilization occurs via the cubicmonoclinic transformation path. It will be the subject of another paper. It is clear that the seed type and pulling rates play an important role in determining not only the microstructure morphology, but also the crystallography. 

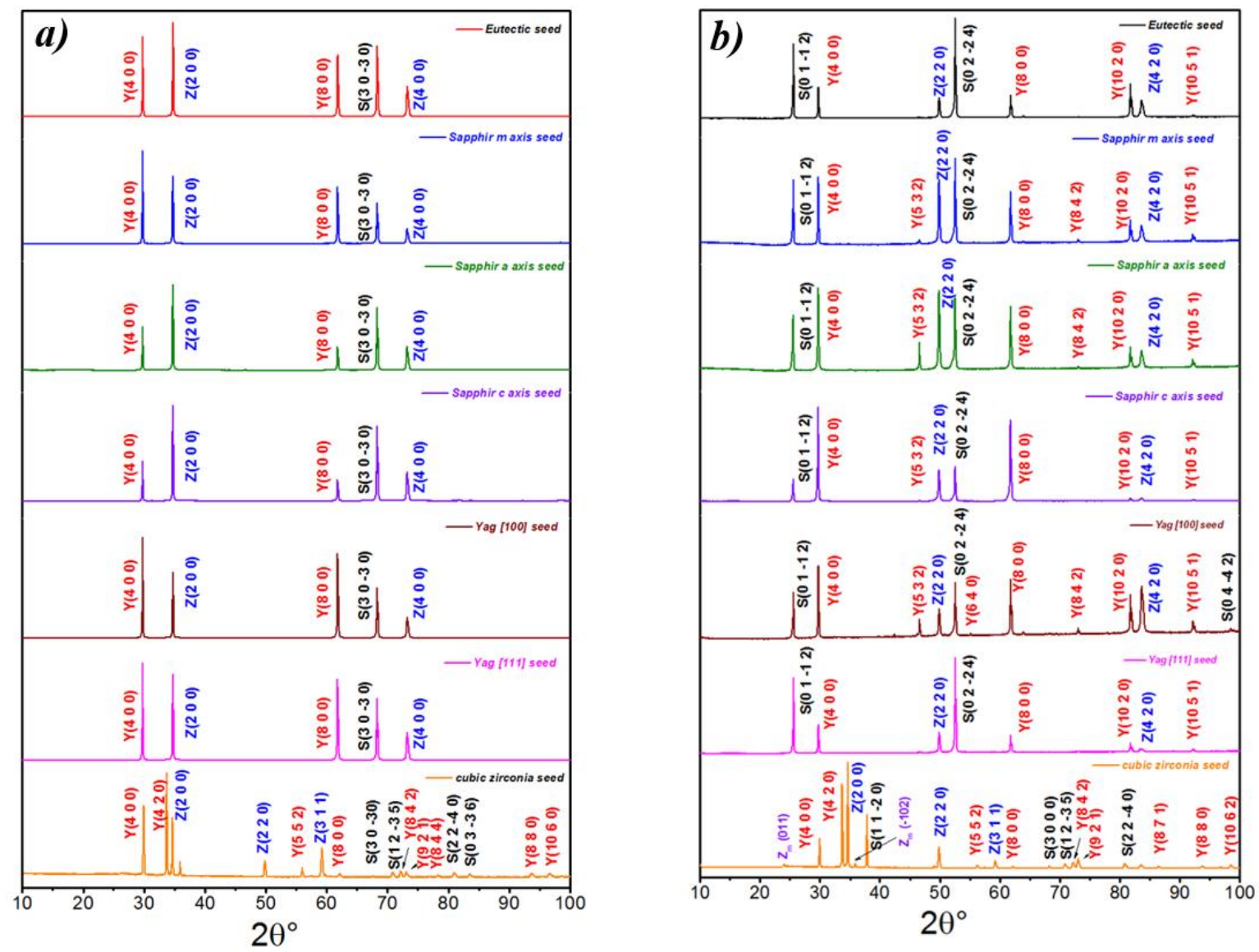

Figure 8. Room temperature bulk XRD patterns of the transversal sections of $\mathrm{Al}_{2} \mathrm{O}_{3} / \mathrm{YAG} / \mathrm{ZrO}_{2}$ eutectic grown by using different seeds. (a) $\mathrm{v}=0.5 \mathrm{~mm} . \mathrm{min}^{-1}$, (b) $\mathrm{v}=0.5 \mathrm{~mm} \cdot \mathrm{min}^{-1}$

\section{3-3 Residual stresses}

The ternary eutectic crystallized from the melt at high temperature and the different reaction occurred during the solidification process leads to the nucleation of three phases with strong interfacial bonding and different thermal expansion coefficient. The origin of the stress in the phases composing the eutectic ceramics is quite often explained by the thermal expansion mismatch between the Sapphire, YAG and $\mathrm{ZrO}_{2}$ phases, which induce a thermal elastic residual stresses during the solidification process. The Thermal expansion coefficient of zirconia $\left(12.6 \times 10-6{ }^{\circ} \mathrm{C}^{-1}\right)$ is higher than alumina $\left(9.2 \times 10-6{ }^{\circ} \mathrm{C}^{-1}\right)$ and YAG $\left(8 \times 10-6{ }^{\circ} \mathrm{C}^{-1}\right)$ $[4,16]$. Because of the low room temperature thermal expansion coefficient difference between alumina and YAG $\left(\Delta \alpha=\alpha\left(\mathrm{Al}_{2} \mathrm{O}_{3}\right)-\alpha(\mathrm{YAG})=1.2 \times 10-6{ }^{\circ} \mathrm{C}^{-1}\right)$, the residual stress in sapphire measured by piezo spectroscopy is about $-70 \mathrm{MPa}$ in $\mathrm{Al}_{2} \mathrm{O}_{3} / \mathrm{YAG}$ binary eutectic $[38,39]$ and becomes $-363 \mathrm{MPa}$ [40] in ternary composite system containing zirconia phases. As a function of seed and pulling rates, Fig 9 shows the evolution of the average hydrostatic stress measured on the transversal section of the samples. Whatever the solidification rate and 
the seed type, the negative values of the hydrostatic stress indicate that the sapphire phase is under compression [16]. The rod solidified through eutectic seed has a stress around -250 $\mathrm{MPa}$ and decrease to $-400 \mathrm{MPa}$ under zirconia seeding at pulling rate of $1 \mathrm{~mm} \cdot \mathrm{min}^{-1}$. Compared to seeding effect, we didn't observed an important impact of the pulling rate. The variation of the residual stresses, not only depends on cooling rate, but also on seed type and orientation. The rods of Chinese script morphology (eutectic, sapphire, YAG) are less compressed than that of cellular structure corresponding to zirconia seeding. The influence of the morphology and the spatial distribution of $\mathrm{ZrO}_{2}$ particles in the microstructure solidified by zirconia seeds strongly affect the residual stresses. The microstructure of the rod grown using $\mathrm{ZrO}_{2}$ seed is formed by a heterogeneous dispersion of irregular $\mathrm{Y}-\mathrm{ZrO}_{2}$ particles within the $\mathrm{Al}_{2} \mathrm{O}_{3}$ matrix. The large thermal stresses generated during solidification by zirconia seed is a consequence of the high axial thermal gradients at the liquid-solid interface often lead to bad surface quality of the samples.

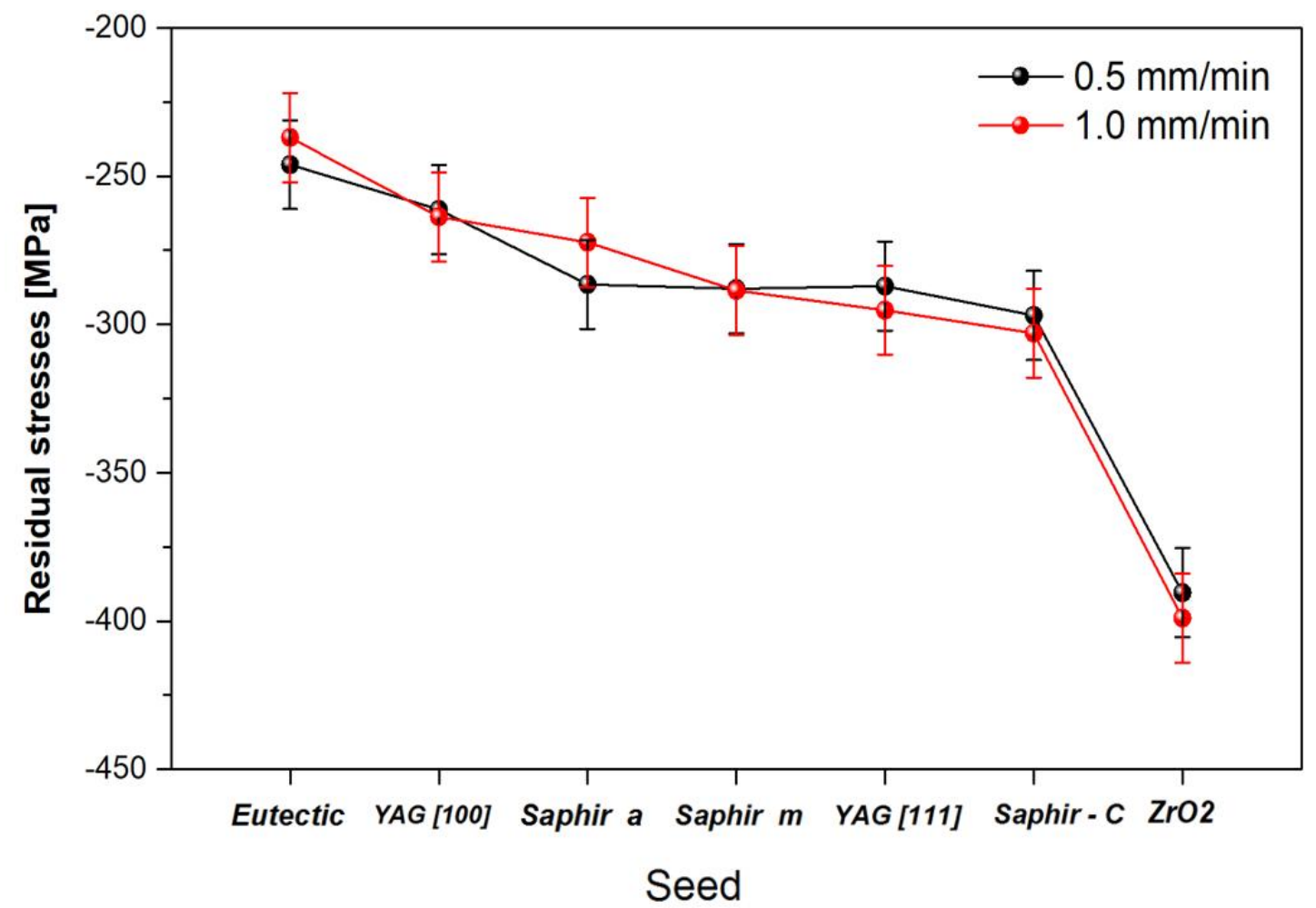

Figure 9. Variation of the residual stresses in the alumina phase (transversal sections), as a function of seeds and pulling rates. 


\section{Conclusion}

In this work, using different oriented seeds $\mathrm{Al}_{2} \mathrm{O}_{3}-\mathrm{YAG}-\mathrm{ZrO}_{2}$ ternary eutectic ceramics was solidified from the melt by using the $\mu$-PD technique. The impact of the type and the orientation of the seed effect on the morphology, the microstructure, the stress and the crystallographic orientations have been investigated. The most important finding is the evolution of the melting zone during the growth and the different phenomena involved near the crystallization front. Following the results, this eutectic system shown that over the range of the composition and seeding three phases growing cooperatively from the liquid. Cooperative growth of the phases with a common interface can be shown to be faster than either phase individually. At pulling rate $0.5 \mathrm{~mm} \cdot \mathrm{min}^{-1}$, whatever the seed type Chinese script microstructure was obtained. On the other hand, at pulling rate $1 \mathrm{~mm} \cdot \mathrm{min}^{-1}$, for (100) YAG and (0001) sapphire seeds, a localized geometrical pattern microstructure was observed. Whatever the seed orientation for pulling rates of 0.5 and $1 \mathrm{~mm} \cdot \mathrm{min}^{-1}$ a few colonies were observed. Through (111) zirconia seeding, due to the entropy of fusion of $\mathrm{ZrO}_{2}$ and off eutectic initial composition, a complex poor irregular cellular microstructure was observed in the entire rods and monoclinic structure was registered at the solidification rate of $1 \mathrm{~mm} \cdot \mathrm{min}^{-1}$. Compressive stress in the irregular cellular microstructure (zirconia seeding) is more important than Chinese script microstructure (eutectic, sapphire and YAG seeding).

\section{Acknowledgements.}

The authors acknowledge the French MAT\&PRO ANR program "CiNATRA" ref: ANR12-RMNP-0008 for financial support. We also thanks M. Podgorski ODGORSKI from SAFRAN for his cooperation and assistance. The authors express their gratitude to Dr A. Nehari and Dr G. Alombert-Goget for their great collaboration and exchange. Thanks to Dr. H. Cabane and M. Dumortier from Cristalinnov for their technical assistance and polishing samples.

\section{References}

[1] W.J. Minford, R.C. Bradt, V.S. Stubican, Crystallography and Microstructure of Directionally Solidified Oxide Eutectics, Journal of the American Ceramic Society. 62 (1979) 154-154. https://doi.org/10.1111/j.1151-2916.1979.tb19043.x. 
[2] C.O. Hulse, J.A. Batt, The Effect of Eutectic Microstructures on the Mechanical Properties of Ceramic Oxides, UNITED AIRCRAFT RESEARCH LABS EAST HARTFORD CT, 1974. https://apps.dtic.mil/sti/citations/AD0781995 (accessed November 12, 2020).

[3] V.S. Stubican, R.C. Bradt, Eutectic Solidification in Ceramic Systems, Annual Review of Materials Science. 11 (1981) 267-297. https://doi.org/10.1146/annurev.ms.11.080181.001411.

[4] J. LLorca, V.M. Orera, Directionally solidified eutectic ceramic oxides, Progress in Materials Science. 51 (2006) 711-809. https://doi.org/10.1016/j.pmatsci.2005.10.002.

[5] N. Nakagawa, H. Ohtsubo, A. Mitani, K. Shimizu, Y. Waku, High temperature strength and thermal stability for melt growth composite, Journal of the European Ceramic Society. 25 (2005) 1251-1257. https://doi.org/10.1016/j.jeurceramsoc.2005.01.030.

[6] Y. Waku, N. Nakagawa, T. Wakamoto, H. Ohtsubo, K. Shimizu, Y. Kohtoku, A ductile ceramic eutectic composite with high strength at 1,873 K, Nature. 389 (1997) 49-52. https://doi.org/10.1038/37937.

[7] B.J. Bayles, J.A. Ford, M.J. Salkind, The effect of elevated-temperature exposure on the microstructure and tensile strength of Al sub 3 Ni whisker-reinforced aluminum(Microstructure stability of aluminum reinforced with Al-Ni whiskers, noting tensile strength and mechanical property dependence on temperature), AIME, TRANSACTIONS. 239 (1967) 844-849.

[8] M. Cherif, Croissance de la céramique eutectique $\mathrm{Al}_{2} \mathrm{O}_{3}-\mathrm{YAG}-\mathrm{ZrO}_{2}: \mathrm{Y}$ et étude de la microstructure Chinese Script, phdthesis, Université Grenoble Alpes, 2016. https://tel.archivesouvertes.fr/tel-01586458 (accessed September 23, 2020).

[9] T. Nagira, H. Yasuda, S. Takeshima, T. Sakimura, Y. Waku, K. Uesugi, Chain structure in the unidirectionally solidified Al2O3-YAG-ZrO2 eutectic composite, Journal of Crystal Growth. 311 (2009) 3765-3770. https://doi.org/10.1016/j.jcrysgro.2009.05.004.

[10] C. Oelgardt, J. Anderson, J.G. Heinrich, G.L. Messing, Sintering, microstructure and mechanical properties of Al2O3-Y2O3-ZrO2 (AYZ) eutectic composition ceramic microcomposites, Journal of the European Ceramic Society. 30 (2010) 649-656. https://doi.org/10.1016/j.jeurceramsoc.2009.09.011.

[11] L. Carroz, T. Duffar, Tuning the sapphire EFG process to the growth of Al2O3/YAG/ZrO2:Y eutectic, Journal of Crystal Growth. 489 (2018) 5-10. https://doi.org/10.1016/j.jcrysgro.2018.02.029.

[12] L. Londaitzbehere, Céramiques eutectiques oxydes à microstructure interconnectée préparées par solidification dirigée : élaboration, microstructure, mécanismes de déformation par fluage et réactivité en présence de vapeur d'eau, phdthesis, Université Paris-Est, 2016. https://tel.archives-ouvertes.fr/tel-01562283 (accessed September 23, 2020).

[13] Y. Waku, S. Sakata, A. Mitani, K. Shimizu, M. Hasebe, Temperature dependence of flexural strength and microstructure of Al2O3/Y3Al5O12/ZrO2 ternary melt growth composites, Journal of Materials Science. 37 (2002) 2975-2982. https://doi.org/10.1023/A:1016073115264.

[14] L. Mazerolles, N. Piquet, M.-F. Trichet, L. Perrière, D. Boivin, M. Parlier, New microstructures in ceramic materials from the melt for high temperature applications, Aerospace Science and Technology. 12 (2008) 499-505. https://doi.org/10.1016/j.ast.2007.12.002. 
[15] J.I. Peña, R.I. Merino, N.R. Harlan, A. Larrea, G.F. de la Fuente, V.M. Orera, Microstructure of Y2O3 doped Al2O3-ZrO2 eutectics grown by the laser floating zone method, Journal of the European Ceramic Society. 22 (2002) 2595-2602. https://doi.org/10.1016/S0955-2219(02)00121-8.

[16] A. Sayir, S.C. Farmer, The effect of the microstructure on mechanical properties of directionally solidified Al2O3/ZrO2(Y2O3) eutectic, Acta Materialia. 48 (2000) 4691-4697. https://doi.org/10.1016/S1359-6454(00)00259-7.

[17] A. Laidoune, K. Lebbou, D. Bahloul, M. Smadi, M. Zereg, Yttria stabilized Al2O3-ZrO2 eutectic crystal fibers grown by the laser heated pedestal growth (LHPG) method, Optical Materials. 32 (2010) 731-734. https://doi.org/10.1016/j.optmat.2010.02.003.

[18] J.H. Lee, A. Yoshikawa, H. Kaiden, K. Lebbou, T. Fukuda, D.H. Yoon, Y. Waku, Microstructure of Y2O3 doped Al2O3/ZrO2 eutectic fibers grown by the micro-pulling-down method, Journal of Crystal Growth. 231 (2001) 179-185. https://doi.org/10.1016/S0022-0248(01)01451-8.

[19] O. Benamara, M. Cherif, T. Duffar, K. Lebbou, Microstructure and crystallography of Al2O3Y3Al5O12-ZrO2 ternary eutectic oxide grown by the micropulling down technique, Journal of Crystal Growth. 429 (2015) 27-34. https://doi.org/10.1016/j.jcrysgro.2015.07.020.

[20] O. Benamara, K. Lebbou, Shaped ceramic eutectic plates grown from the melt and their properties, Journal of Crystal Growth. 449 (2016) 67-74.

https://doi.org/10.1016/j.jcrysgro.2016.05.046.

[21] S.M. Lakiza, L.M. Lopato, Stable and Metastable Phase Relations in the System AluminaZirconia-Yttria, Journal of the American Ceramic Society. 80 (1997) 893-902.

https://doi.org/10.1111/j.1151-2916.1997.tb02919.x.

[22] J. He, D.R. Clarke, Polarization Dependence of the Cr3+ R-Line Fluorescence from Sapphire and Its Application to Crystal Orientation and Piezospectroscopic Measurement, Journal of the American Ceramic Society. 80 (1997) 69-78. https://doi.org/10.1111/j.1151-2916.1997.tb02792.x.

[23] H. Su, J. Zhang, C. Cui, L. Liu, H. Fu, Rapid solidification of Al2O3/Y3Al5O12/ZrO2 eutectic in situ composites by laser zone remelting, Journal of Crystal Growth. 307 (2007) 448-456. https://doi.org/10.1016/j.jcrysgro.2007.06.029.

[24] E.M. Levin, H.F. McMurdie, Phase diagrams for ceramists, 1975 supplement, (1975). https://www.osti.gov/biblio/7351343 (accessed November 12, 2020).

[25] D. Viechnicki, F. Schmid, Eutectic solidification in the system Al2O3/Y3Al5O12, J Mater Sci. 4 (1969) 84-88. https://doi.org/10.1007/BF00555053.

[26] M. Cherif, T. Duffar, L. Carroz, P. Lhuissier, E. Bautista-Quisbert, On the growth and structure of Al2O3-Y3Al5O12-ZrO2:Y solidified eutectic, Journal of the European Ceramic Society. 40 (2020) 31723180. https://doi.org/10.1016/j.jeurceramsoc.2020.03.025.

[27] J.H. Lee, A. Yoshikawa, T. Fukuda, Y. Waku, Growth and characterization of Al2O3/Y3Al5O12/ZrO2 ternary eutectic fibers, Journal of Crystal Growth. 231 (2001) 115-120. https://doi.org/10.1016/S0022-0248(01)01375-6.

[28] X. Wang, Y. Zhong, Q. Sun, Y. Li, W. Zhang, D. Qi, D. Wang, B. Jiang, Crystallography and interfacial structure in a directionally solidified Al2O3/Y3Al5O12/ZrO2 eutectic crystal, Scripta Materialia. 145 (2018) 23-27. https://doi.org/10.1016/j.scriptamat.2017.10.008. 
[29] J.I. Peña, M. Larsson, R.I. Merino, I. de Francisco, V.M. Orera, J. LLorca, J.Y. Pastor, A. Martín, J. Segurado, Processing, microstructure and mechanical properties of directionally-solidified Al2O3Y3Al5012-ZrO2 ternary eutectics, Journal of the European Ceramic Society. 26 (2006) 3113-3121. https://doi.org/10.1016/j.jeurceramsoc.2005.11.005.

[30] J.M. Calderon-Moreno, M. Yoshimura, Al2O3-Y3Al5O12(YAG)-ZrO2 ternary composite rapidly solidified from the eutectic melt, Journal of the European Ceramic Society. 25 (2005) 13651368. https://doi.org/10.1016/j.jeurceramsoc.2005.01.012.

[31] F.J. Ester, A. Larrea, R.I. Merino, Processing and microstructural study of surface laser remelted Al2O3-YSZ-YAG eutectic plates, Journal of the European Ceramic Society. 31 (2011) 12571268. https://doi.org/10.1016/j.jeurceramsoc.2010.08.016.

[32] X. Fu, G. Chen, Y. Zu, J. Luo, W. Zhou, Microstructure refinement approaches of melt-grown Al2O3/YAG/ZrO2 eutectic bulk, Ceramics International. 39 (2013) 7445-7452. https://doi.org/10.1016/j.ceramint.2013.02.089.

[33] K. Song, J. Zhang, X. Jia, H. Su, L. Liu, H. Fu, Longitudinal cross-section microstructure of growth striation in Al2O3/Y3Al5O12/ZrO2 directionally solidified eutectic ceramic prepared by laser floating zone, Journal of the European Ceramic Society. 33 (2013) 1123-1128. https://doi.org/10.1016/j.jeurceramsoc.2012.12.003.

[34] B.A. Gnesin, M.Y. Starostin, Textures of Phases in Al2O3 - ZrO2 (Y2O3) Eutectic Composites, Textures and Microstructures. 25 (1995) 25-32. https://doi.org/10.1155/TSM.25.25.

[35] Rosa I. Merino, Isabel De Francisco, José I Peña, Solid State Ionics 178 (2007) 239-247, doi: 10.1016/j.SSI.2006.12.017

[36] L. Mazerolles, L. Perriere, S. Lartigue-Korinek, N. Piquet, M. Parlier, Microstructures, crystallography of interfaces, and creep behavior of melt-growth composites, Journal of the European Ceramic Society. 28 (2008) 2301-2308. https://doi.org/10.1016/j.jeurceramsoc.2008.01.014.

[37] J. Selsing, Internal Stresses in Ceramics, Journal of the American Ceramic Society. 44 (1961) 419-419. https://doi.org/10.1111/j.1151-2916.1961.tb15475.x.

[38] G. Gouadec, K. Makaoui, L. Perrière, P. Colomban, L. Mazerolles, Ruby micropiezospectroscopy in GdAlO3/Al2O3(/ZrO2), Er3Al5O12/Al2O3(/ZrO2) and Y3Al5O12/Al2O3(/ZrO2) binary and ternary directionally solidified eutectics, Journal of the European Ceramic Society. 32 (2012) 2145-2151. https://doi.org/10.1016/j.jeurceramsoc.2012.01.038.

[39] E.C. Dickey, C.S. Frazer, T.R. Watkins, C.R. Hubbard, Residual stresses in high-temperature ceramic eutectics, Journal of the European Ceramic Society. 19 (1999) 2503-2509. https://doi.org/10.1016/S0955-2219(99)00100-4.

[40] J.A. Pardo, R.I. Merino, V.M. Orera, J.I. Peña, C. González, J.Y. Pastor, J. LLorca, Piezospectroscopic Study of Residual Stresses in Al2O3-ZrO2 Directionally Solidified Eutectics, Journal of the American Ceramic Society. 83 (2000) 2745-2752. https://doi.org/10.1111/j.11512916.2000.tb01626.x. 